\title{
Perspectivas do Plano Nacional de Turismo 2007/2010: avanços ou utopias?
}

\section{Perspective of National Tourism Plan 2007/2010: advances or utopias?}

\author{
Heidi Gracielle Kanitz ${ }^{1}$ \\ Renata Paula Costa Trigueiro ${ }^{2}$ \\ Maria Arlete Duarte de Araújo ${ }^{3}$
}

\begin{abstract}
Resumo
Este artigo objetivou discutir o conteúdo dos macroprogramas do PNT 2007/2010 com base em três categorias: o turismo como fator de inclusão, de geração de emprego e renda, e como atividade que proporciona crescimento/desenvolvimento às localidades envolvidas. Foi um estudo de natureza exploratória e descritiva, de abordagem qualitativa. Os dados foram coletados do Plano Nacional de Turismo 2007/2010 através da análise documental. No tratamento das informações foi utilizada a análise categorial que é uma das técnicas da análise de conteúdo. Verificou-se que o turismo pode ser indutor de inclusão social, gerar emprego, renda e contribuir para o desenvolvimento, desde que haja integração do poder público, iniciativa privada e população local. Conclui-se que os benefícios advindos do turismo podem ocorrer em médio prazo, em função da lógica de exclusão imposta pela economia mundial.
\end{abstract}

Palavras-chave: Plano Nacional de Turismo; inclusão social; emprego e renda; crescimento; desenvolvimento.

\footnotetext{
Abstract

This article aimed to discuss the content of the macro programs PNT 2007/2010 based on three categories: the tourism as factor of inclusion, producer of employment and income, and as activity able to lead growth and development to locations involved. It was a study of exploratory and descriptive, qualitative approach. Data were collected from the National Tourism Plan 2007/2010 by documental analysis. At information's treatment was used category analysis. This is one of the techniques of content analysis. It was found that tourism

${ }^{1}$ Turismóloga graduada pela Universidade Federal do Rio Grande do Norte (UFRN). Mestre em Administração pela UFRN. Email: heidi_kanitz@yahoo.com.br.

${ }^{2}$ Turismóloga graduada pela Universidade Federal do Rio Grande do Norte (UFRN). Mestre em Administração pela UFRN. Email: renatapctrigueiro@yahoo.com.br.

3 Administradora graduada pela Universidade Federal de Sergipe (UFS). Mestre em Administração pela Universidade Federal da Paraíba (UFPB). Doutora em Administração de Empresas pela Fundação Getúlio Vargas-SP. Professora Doutora do Programa de Pós-Graduação em Administração da UFRN. Email: dfb@digi.com.br.
} 
can be inducers of social inclusion, generates employment, incomes and contributes to the development, subject to the integration of government, private sector and local population. The conclusion was the benefits of tourism will only occur in the medium term, due to the logic of exclusion imposed by the global economy.

Keywords: National Tourism Plan; social inclusion; employment and income; growth and development.

\section{Introdução}

O turismo configura-se como um dos mais importantes e promissores segmentos econômicos do país, apresentando taxas de crescimento percentuais superiores à média mundial em termos de fluxo turístico receptivo, receita turística cambial e geração de empregos (OMT, 2001)

A atividade turística, assim como outras formas de atividade econômica, existe em um ambiente moldado por muitas forças distintas. Uma das forças mais importantes se manifesta através de uma rede complexa de políticas, leis, regulamentações e outras ações dos governos. Por incorporar um amplo conjunto de atividades da competência de diferentes atores e agências estatais e privados, as políticas públicas em turismo são, por excelência, multisetoriais e, na sua implementação, tornam-se extremamente complexas. Podemos encontrar programas, projetos e atividades em outras políticas setoriais com forte rebatimento sobre o turismo, como é o caso da infra-estrutura, das políticas urbanas, de desenvolvimento regional, de emprego e renda e, mais recentemente, de preservação ambiental e do patrimônio cultural.

Sendo assim, a presença de uma política nacional de turismo é importante para estabelecer as metas e direcionar o desenvolvimento do setor. Através das políticas, os governos podem articular seus objetivos para o turismo e suas preocupações com relação a seus impactos, sejam eles positivos ou negativos.

Muito se tem discutido sobre o papel do turismo como atividade potencialmente destruidora de paisagens e do meio ambiente natural, por não dizer do ambiente cultural dos povos visitados. Contudo, se por um lado as discussões sobre os impactos negativos da atividade 


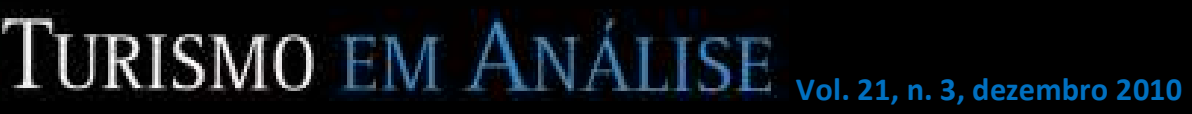

646

turística sobre o entorno natural das localidades visitadas são acaloradas, por outro, de acordo com Silveira (1999), poucos se perguntaram alguma vez se o crescimento econômico trazido pelo turismo promove a distribuição de renda de modo mais equânime, ou seja, se contribui para a redução da pobreza e a conseqüente melhoria das condições de vida da população como um todo, e não apenas de uma pequena parcela. Acredita-se ainda no turismo como tábua de salvação, discurso este bastante utilizado pelos governos, em especial os de países em vias de desenvolvimento, sendo encarado como a grande alternativa possível de política econômica.

Krippendorf (2000) afirma que uma visão mais crítica e menos ingênua a respeito do turismo é fenômeno recente. Segundo este autor, a partir dos anos 1960 os países industrializados passaram a experimentar um crescimento desenfreado do turismo, devido principalmente às inovações nos meios de transporte e de comunicação, ao aumento do tempo livre e de lazer, do bem-estar social e do poder de compra, entre outros fatores. Com isso, o turismo passou a ser visto como possibilidade de resolução para os problemas econômicos, e inúmeros países, regiões e empresas passaram a tentar participar desse "filão":

Para todos, a empresa turística representava a grande oportunidade, o meio bem merecido de compensar todos os anos de guerra e de crise, a possibilidade tão esperada de iniciar, enfim, o desenvolvimento econômico e obter vantagens com o estímulo que significavam as divisas estrangeiras. (KRIPPENDORF, 2000, p. 96)

Embora as conseqüências da atividade turística nas localidades receptoras tenham sido analisadas na época, tais estudos limitavam-se apenas aos aspectos econômicos. Somente a partir dos anos 1970 é que a sociedade passou a se dar conta das mazelas inerentes ao turismo, em virtude da fragilidade ou ausência de planejamento de políticas públicas específicas bem como órgãos competentes diretamente ligados ao turismo.

A criação do Ministério do Turismo em 01/01/2003 (Medida Provisória $n^{\circ} 103$ ), primeiro dia do mandato do governo Lula, é emblemática do status conferido por este governo ao turismo 
na administração pública federal, uma vez que, pela primeira vez na história do país o turismo tem um Ministério todo para si.

Com a criação do Ministério do Turismo, foi implementado o "Plano Nacional do Turismo Diretrizes, Metas e Programas", que estabeleceu os rumos para o desenvolvimento da atividade turística no Brasil para o período 2003/2007.

Assim, como afirma Santana apud Silveira (2005, p.5):

With the introduction of the PNT (National Tourism Policy), Brazil has for the first time a clear national policy for tourism, which had as macro strategies: the planning, development, and promotion of tourism through the articulation of the government and the private sector; the implementation of basic and tourism infrastructure; the training of human resources in tourism in general; and the decentralization and modernization of tourism administration.

Desta forma, o Plano Nacional de Turismo configurou-se como o principal documento no país a reger a atividade turística, apontando diretrizes para que os governos estaduais, secretarias e demais atores envolvidos pudessem nortear suas políticas públicas. As metas alcançadas e os resultados gerados através deste primeiro documento deram a base necessária para que fossem reformuladas algumas questões e, a partir disso, se construísse um novo documento, o Plano Nacional de Turismo 2007/2010. Tal plano contempla alguns assuntos antes não previstos, tais como a questão da acessibilidade para portadores de necessidades especiais, trazendo ainda modificações importantes em seu corpo metodológico e uma melhor adequação das metas à realidade do país.

Com base em um diagnóstico dos problemas enfrentados pelo setor de turismo (MTUR, 2007), foram estabelecidos objetivos gerais e específicos, dentre os quais se destacam: desenvolver o produto turístico brasileiro com qualidade, contemplando as diversidades regionais, culturais e naturais; promover o turismo com um fator de inclusão social, por meio da geração de trabalho e renda e pela inclusão da atividade na pauta de consumo de todos os 
brasileiros; fomentar a competitividade do produto turístico brasileiro nos mercados nacional e internacional e atrair divisas para o País.

O Ministério do Turismo se orienta pelas diretrizes definidas no Plano Nacional de Turismo, estruturado por um conjunto de macroprogramas e programas que, alinhados com os programas e as ações do Plano Plurianual de Governo, estabelecem, segundo o documento, as condições para a sua efetivação no âmbito do governo federal. As metas para o período 2007/2010 apresentam-se da seguinte maneira: Meta 1: promover a realização de 217 milhões de viagens no mercado interno; Meta 2: criar 1,7 milhão de novos empregos e ocupações (sendo esta cumulativa); Meta 3: estruturar 65 destinos turísticos com padrão de qualidade internacional; Meta 4: gerar 7,7 bilhões de dólares em divisas (MTUR, 2007).

Tais metas do PNT são orientadas por 8 (oito) macroprogramas, a saber: Informação e Estudos Turísticos, Planejamento e Gestão, Logística de Transportes, Regionalização do Turismo, Fomento à Iniciativa Privada, Infraestrutura Pública, Qualificação dos Equipamentos e Serviços Turísticos e Promoção e Apoio à Comercialização.

Nesta perspectiva, este artigo teve por objetivo discutir o conteúdo dos macroprogramas supracitados com base em três categorias: o turismo como fator de inclusão, como fonte geradora de emprego e renda e como atividade que proporciona crescimento/desenvolvimento a uma localidade.

Diante deste objetivo proposto, a pesquisa se classifica como um estudo de natureza exploratória e descritiva, de abordagem qualitativa. Conforme explica Mattar (1996, p.18), a pesquisa exploratória "visa prover o pesquisador de maior conhecimento sobre o tema ou problema de pesquisa em perspectiva". Para Barros e Lehfeld (2000) pesquisa descritiva é aquela em que o pesquisador não interfere, ou seja, ele descreve o objeto de pesquisa relatando a freqüência com que o mesmo ocorre, sua natureza, características, causas, relações e conexões com outros fenômenos. Já a pesquisa qualitativa busca o aprofundamento das causas que envolvem o fenômeno estudado, isto é, ela não se limita à quantificação estatística dos dados coletados, mas à compreensão dos significados do problema investigado (ALVESMAZZOTTI; GEWANDSZNAJDER, 1998). 
Os dados foram coletados a partir do Plano Nacional de Turismo 2007/2010 através da análise documental. Segundo Bardin (1977) a análise documental é aquela realizada a partir de documentos, contemporâneos ou retrospectivos, considerados cientificamente autênticos.

A análise dos dados coletados foi realizada de forma qualitativa. Para tanto, utilizou-se o procedimento metodológico proposto por Bardin (1977) em uma das técnicas da análise de conteúdo denominada análise categorial. De acordo com Roesch (1996), a análise de conteúdo classifica, categoriza palavras, frases ou mesmo parágrafos. Para Bardin (1977) a análise de conteúdo é um conjunto de técnicas de análise das comunicações visando obter, por procedimento, sistemáticos e objetivos de descrição do conteúdo das mensagens, indicadores (quantitativos ou não) que permitam a inferência de conhecimentos relativos às condições de produção/recepção destas mensagens.

Ainda segundo Bardin (1977) a análise categorial funciona por operações de desmembramentos do texto em unidades, em categorias segundo reagrupamentos analógicos. Entre as diferentes possibilidades de categorização, a investigação de temas, ou análise temática, é rápida e eficaz na condição de se aplicar a discursos diretos (significações manifestas) e simples.

Através desta técnica, foram criadas três categorias de análise para analisar as propostas e fundamentações do Plano Nacional de Turismo, quais sejam: turismo como fator de geração de emprego e renda; turismo como fator de inclusão, e; turismo como fator de crescimento/desenvolvimento.

Neste sentido, faz-se mister destacar que o ensaio a ser desenvolvido neste artigo está centrado no binômio "geração de empregos e renda", bem como na discussão "turismo como fator de inclusão e desenvolvimento" por tratarem-se estes dos jargões mais utilizados em prol do turismo, seja pelo poder público, seja por defensores da atividade de um modo geral, uma vez que de fato constituem estes seus efeitos positivos mais visíveis e diretos, acorde Rabahy (2003)

A relevância desse despertar justifica-se pelo fato de existir um certo consenso geral de que o turismo é uma atividade 'limpa', capaz de crescer rapidamente e, neste processo, garantir à 
comunidade receptora o aumento de empregos e renda, como se tratasse apenas de uma receita pré-estabelecida que pudesse ser reproduzida com sucesso em qualquer lugar. Nesse sentido, percebe-se como os aspectos econômicos ainda são supervalorizados em detrimento de todos os outros, pelos governos que se lançam nessa verdadeira corrida, sem importar-se com os riscos e conseqüências negativas intrínsecas a toda e qualquer atividade econômica, e ignorando, outrossim, que o crescimento econômico, por si só, não é capaz de gerar desenvolvimento.

O artigo encontra-se estruturado da seguinte forma, a partir desta introdução: um capítulo que contempla uma discussão acerca da inclusão pelo turismo, seguido de uma exposição sobre o binômio emprego-renda e sua relação com o turismo, contemplando logo após um capítulo com breves considerações acerca do turismo e sua capacidade de proporcionar crescimento/desenvolvimento à uma localidade. Logo após, segue a análise de conteúdo do PNT dentro das categorias supracitadas, finalizando com a conclusão acerca do exposto.

\section{A Inclusão pelo Turismo}

O turismo é considerado uma atividade capitalista que interfere na organização dos espaços, de forma positiva ou negativamente. Para ordenar e minimizar esses impactos, se faz necessário o controle do governo, da iniciativa privada e da própria comunidade onde a atividade turística está inserida. Essa atividade, enquanto produtora e produto do capitalismo contemporâneo, reproduz relações sociais excludentes. A maioria da população está excluída não somente das oportunidades de participar dos frutos da riqueza gerada, mas também da produção da riqueza (MARTINS, 2002).

A necessidade de inclusão só existe porque há exclusão. Nesse sentido, a inclusão social parte do pressuposto que há pessoas excluídas ou há fatores excludentes. O que acontece de fato é que os excluídos não se encontram excluídos da dinâmica capitalista, pois são elementos fundamentais para a manutenção do sistema, isto é, não é que seja natural haver pobres e ricos, incluídos e excluídos. Ocorre que o modelo de desenvolvimento foi planejado para 
concentrar riquezas e ao fazê-lo produz essa contradição, própria do sistema, que alimenta a vida econômica, social e política (YAZBEK, 2001; CORIOLANO, 2005).

Para Oliveira (2008, p. 93),

o significado de inclusão social é inserir, abranger, introduzir e integrar toda a sociedade. Integrar significa ser participante, ser considerado, fazer parte de um todo em condições semelhantes. A integração requer a promoção das qualidades próprias de um indivíduo, sem segregação.

Quando a expressão inclusão social é utilizada não se considera somente os portadores de necessidades especiais, mas sim, as pessoas, sem distinção de raça, crença, condição sócioeconômica, idade, sexo, preferência sexual, etc. A inclusão social é o que pode se chamar de processo de atitudes afirmativas, no sentido de inserir os menos favorecidos no contexto social.

O turismo enquanto espaço de valorização do capital também segue a regra de inclusão/exclusão, do ponto de vista que a prática da atividade turística (lazer, entretenimento, viagens, acesso a eventos culturais, etc.) ainda é vista como uma atividade realizada por poucos e como um elemento superficial, o que leva a concluir que privilegiar apenas uma parcela desse fenômeno tão complexo e dinâmico pode causar problemas graves para a implantação e o desenvolvimento de um turismo articulado com outras atividades da economia, que seja sustentável e duradouro (TRIGO; NETTO, 2003). É nesse sentido que o governo propõe planos e programas para a inclusão social, como é o caso do Plano Nacional de Turismo 2007/2010, que tem como objetivo principal promover a inclusão social, visando garantir o acesso ao turismo para aposentados, trabalhadores e estudantes através de roteiros e pacotes financiados em condições facilitadas, fortalecendo assim o turismo interno e através disso buscando assegurar mais condições para a promoção do Brasil no exterior.

Nesse sentido, Ruschmann (1997) defende que o turismo deve ser incorporado às conquistas sociais fundamentais, que neste caso se relacionam com o turismo popular social. Além disso, 
a qualidade de vida dos cidadãos deve alcançar níveis desejáveis em todos os campos: físico, cultural, social e psíquico.

Coriolano (2005, p.302) afirma que o acesso ao turismo está, aos poucos, se tornando comum a todos, quando aponta que:

a cada dia, grupos alternativos começam a se organizar para o usufruto de novos produtos turísticos, de novos roteiros e dos mais variados produtos do consumo turístico que começam a participar desse mercado. Municípios, comunidades e pequenas empresas encontram caminhos para se incluir nos roteiros turísticos e aproveitar artes, gastronomias, folclores, atrativos naturais e culturais, transformando o potencial em oferta. $\mathrm{O}$ turismo chegou aos morros, favelas, áreas indígenas, assentamentos dos sem terra e às periferias. Os excluídos do turismo das elites inventam o turismo social, o turismo dos trabalhadores, adaptado às condições econômicas dos pequenos rendimentos, tentando incluir-se na base do sistema.

O turismo com características sociais, ou seja, o conjunto de relações e fenômenos resultantes da participação de camadas sociais menos favorecidas no turismo é uma atividade reconhecida como importante pelo Código Mundial de Ética do Turismo, adotado pela OMT. Segundo os respectivos parágrafos 3 e 4 do artigo $7^{\circ}$ - Direito do Turismo do Código já referido, "o turismo social, e em especial o turismo associativo, permite o acesso de grande número de pessoas ao lazer, às viagens e às férias e deve ser desenvolvido com o apoio das autoridades públicas" (parágrafo 3) e "o turismo familiar, juvenil e estudantil, de pessoas maiores de 65 anos e pessoas portadoras de necessidades especiais deve ser estimulado e facilitado" (parágrafo 4). Dessa forma, a prática do turismo com características sociais implica na democratização do turismo, contribuindo contra as injustiças e contra a exclusão, uma vez que favorece a integração social (OMT, 1998).

Contudo, sabe-se que a inclusão social promovida pelo turismo é uma mudança a médio prazo, pois a lógica da economia mundial traçou os parâmetros atuais, onde a inclusão é para alguns e a exclusão para muitos, visto que o modelo concentrador de riquezas possibilita para algumas pessoas e grupos o acesso a bens e serviços essenciais, à segurança, à justiça e vida política, mas ao mesmo tempo nega a muitos as condições de sobrevivência. 


\section{O Turismo e a Geração de Emprego e Renda}

O turismo é uma atividade complexa, não só pela quantidade de elementos que a compõe, mas, também, pelos diversos setores da economia envolvidos. Nesse sentido, a atividade turística, segundo Andrade (1995), corresponde ao conjunto de serviços que têm por objetivo a promoção e a execução de viagens, os serviços de recepção, hospedagem e atendimento aos indivíduos e grupos fora de suas residências habituais. Nesse contexto gera renda, favorece a criação de empregos, entrada de divisas que ajudam a equilibrar a balança de pagamentos, aumenta os impostos públicos e acelera a atividade empresarial. Desse modo, o turismo tem grande importância na economia devido à sua elevada contribuição para a geração de valor agregado bruto (OMT, 2001).

A evolução do mundo moderno, que estreitou as distâncias geográficas, principalmente pela melhoria dos sistemas de transportes e comunicações, ampliou o significado do turismo. Ele deixou de ser sinônimo de lazer para assumir o papel de agente social, político e econômico, onde em muitos países é a força vital do desenvolvimento. Nesse sentido Wahab (1991, p.23) afirma que o turismo

é muito mais do que uma indústria de serviços, pois o produto turístico é a composição de uma base cultural com herança histórica, meio ambiente diverso, beleza natural, paisagens atraentes, boa hospitalidade, acomodações confortáveis e uma boa cozinha.

De acordo com a Organização Mundial do Turismo apud Embratur (2008), em 2006 houveram 847,3 milhões de deslocamentos físicos no mundo, decorrentes da atividade turística, o que corresponde a US\$ 742,2 bilhões em receita cambial gerada pelo turismo. Nesse mesmo período no Brasil o fluxo receptivo internacional de turistas foi de 5 milhões, o que corresponde a US\$ 4,3 bilhões em receita cambial. Ainda em 2006, o desembarque de passageiros de vôos nacionais foi de 46,3 milhões, 7,54\% acima do verificado no mesmo período do ano anterior, quando o número de passageiros desembarcados foi de 43,1 milhões. Além disso, o turismo é a atividade que mais emprega no mundo, cerca de 240 milhões de pessoas ou $10 \%$ da força de trabalho global (EMBRATUR, 2008). 
Para Arendit (2002), o turismo é um grande gerador de empregos, visto que utiliza mão-deobra intensiva e pelo fato de que a tendência à automação nesse setor, comparativamente ao segmento industrial, é bem menor. O Banco Mundial Brasil (2003) compartilha com essa opinião otimista, argumentando que o desenvolvimento do setor turístico pode ser particularmente apropriado para a redução da pobreza, em especial devido à grande quantidade de vagas de trabalho criadas, que em nível mundial absorvem 1 em 14 trabalhadores. Como visto, o turismo é uma atividade capaz de oferecer um rápido crescimento econômico em termos de nível de emprego, distribuição mais justa de riqueza, melhoria da qualidade de vida e incremento de alguns setores industriais ligados à atividade turística. No entanto, tais crenças e visões são passíveis de críticas.

\section{Turismo: fonte de crescimento ou desenvolvimento?}

É fato que a criação de postos de trabalho consiste em um dos benefícios mais procurados quando os governos buscam incentivar a atividade turística em seus territórios. Primeiro, devido ao elevado nível de desemprego que aflige a sociedade em nível mundial; segundo, porque a população receptora se beneficia da renda gerada pelo turismo através dos rendimentos obtidos com as ocupações ligadas ao setor.

Fernandes e Coelho (2002) acreditam que o turismo tem evoluído de tal modo, especialmente a partir da segunda metade do século XX, que é considerado na atualidade o segmento que exibe um dos maiores níveis de crescimento no mundo dos negócios. Crescimento este capaz de gerar uma receita internacional na ordem de US\$742,2 bilhões, segundo dados mais recentes da Organização Mundial do Turismo (apud EMBRATUR, 2008), graças a uma mobilização social em massa de 847 milhões de viajantes em todo o planeta. Esse quadro positivo tem proporcionado uma mudança de perspectiva do turismo enquanto atividade econômica, passando este a ser visto por muitos governos, em especial o de países mais pobres, não apenas como uma alternativa às crises financeiras, mas como uma tábua de salvação segura e imediata para os seus problemas sociais. 
Parece que o crescimento é, a priori, o remédio miraculoso à pobreza, por duas razões: aumenta o emprego e cresce a produtividade e com ela os salários (EDWARDS, 1995 apud SALAMA, 2002, p.180). Como apontam Fernandes e Coelho (2002), muitos países de economia mais fraca almejam o desenvolvimento econômico, e com o objetivo de atingir esse fim, apostam no turismo todas as suas fichas desejosos de obter o progresso econômico a qualquer custo. No entanto, Dantas (2001) questiona se o crescimento econômico implica necessariamente em desenvolvimento, se o mero fato de uma atividade gerar empregos e renda denota que a mesma levará o desenvolvimento à uma localidade ou região.

De fato, a noção de que o crescimento econômico leva ao desenvolvimento virou um adágio repetido desde conversas entre cidadãos comuns e preleções governamentais até obras de literatura econômica. Assim, o desenvolvimento como conseqüência direta e inexorável do crescimento econômico apresenta-se quase como uma tradição popular a permear as gerações. Isso talvez ocorra devido à dificuldade de se conceituar e medir com precisão os conceitos de desenvolvimento e subdesenvolvimento, dificuldade esta que, como afirma Dantas (2001), resulta na tendência natural de se relacionar tais conceitos abstratos a elementos mais tangíveis e palpáveis como níveis de renda e de empregos.

Mochon e Troster (1994) opinam que, para haver desenvolvimento, faz-se necessário aplicar os recursos econômicos obtidos com o crescimento em transformações sociais, de modo a alcançar uma melhoria na qualidade de vida da população como um todo: “desenvolvimento é o processo de crescimento de uma economia, ao longo do qual de se aplicam novas tecnologias e se produzem transformações sociais, que acarretam uma melhor distribuição da riqueza e da renda" (MOCHON; TROSTER, 1994, p.331). Oliveira (2002) também afirma que, para que haja desenvolvimento, faz-se necessário que exista uma participação de todos na riqueza produzida, e não apenas o crescimento dessa riqueza.

De acordo com Faria (2001, p. 99),

há uma situação de extrema complexidade no que se refere a situações de exclusão, desigualdade, discriminação e vulnerabilidade. Na verdade, em razão da heterogeneidade do País e dado o seu processo histórico de desenvolvimento, o que se tem é uma estrutura sumamente complexa de situações de exclusão. 
Sendo assim, quaisquer políticas sociais, nelas inclusas as ações provenientes das políticas públicas de turismo, têm que enfrentar uma situação bastante ampla, difícil e complexa: desigualdades muito profundas, níveis de exclusão significativos, uma quantidade muito grande de pobres e grupos em situações diferentes de vulnerabilidade.

Therborn et al (2003) já afirmavam que era evidente o fato de que a pobreza tem crescido enormemente nos países do Terceiro Mundo

mas não somente neles. [...] Ainda mais grave é o fato de as desigualdades terem se intensificado entre os próprios pobres. Estamos diante de um processo novo: a pauperização da pobreza, dos setores que são, hoje, muito mais pobres do que antes (THERBORN et al, 2003, p. 143).

Desenvolvimento turístico, portanto, não é - como não poderia ser - sinônimo de desenvolvimento econômico-social. Nenhuma atividade econômica setorial pode garantir esse desenvolvimento, já que no imenso jogo de relações que comanda esse processo, cada uma dessas atividades representa apenas uma parte. Sendo assim, Bramwell (2002) ressalta que as políticas devem ser integradas umas nas outras, baseadas no reconhecimento da interdependência dos problemas e das políticas, tais como turismo, emprego, transporte, entre outras.

\section{Apreciação Crítica e Reflexões Acerca do Plano Nacional de Turismo}

\subsection{Categoria 1: turismo como fator de geração de emprego e renda}

Os sujeitos produtores do turismo possuem ideologias que sustentam políticas e estratégias, posturas diferenciadas em relação ao fenômeno, perceptíveis em seus discursos e práticas. Para alguns grupos sociais, o turismo representa uma atividade redentora, enquanto outros a consideram uma ação devastadora da natureza e comprometedora da sociedade. Existem os que o entende como atividade puramente econômica, diferente daqueles que o concebe como 
essencialmente cultural. Por um determinado ângulo de entendimento, pode ser uma atividade concentradora de renda, ao contrário da óptica que o defende como distribuidor de empregos e ganhos (CORIOLANO, 2006). De acordo com os interesses e visões de mundo, os grupos criam sistemas de representações, de significados, produzindo os discursos, referendando as práticas sociais e estratégias políticas, embora nem sempre esses discursos tenham o mesmo sentido das práticas e os grupos não estejam coesos sobre o assunto.

Nas duas últimas décadas, foi construída uma referência discursiva sobre o turismo, levando a considerar sobre seus impactos no crescimento econômico, na geração de emprego e renda e na contribuição ao desenvolvimento. Essas idéias são repetidas e tornaram-se discurso coletivo, pois este permeou a fala dos sujeitos sociais do turismo: dos governos, empresários e mesmo das comunidades (CORIOLANO, 2006). Este é o caso do PNT 2007/2010, exemplificado nos trechos a seguir:

O turismo é uma atividade de importância fundamental para o crescimento da economia do País devido não somente a sua contribuição significativa para o aumento do PIB, como também pela potencial capacidade de geração de trabalho, ocupação e renda, com impactos na melhoria da qualidade de vida da população.

Entre as contribuições mais expressivas decorrentes do desenvolvimento do turismo no quadriênio 2007/2010, que terão uma grande repercussão no desenvolvimento socioeconômico do País, destacam-se a geração de US\$ 25,3 bilhões em divisas e a criação de 1,7 milhão de novos empregos e ocupações, de acordo com as metas traçadas pelo Plano Nacional de Turismo.

Nos anos de 2003 a 2006, foram gerados pela atividade turística no Brasil 891.000 empregos, formais e informais, o que indica que a meta de geração de 1,7 milhão de empregos e ocupações, até 2007, definida no Plano Nacional de Turismo 2003/2007, deverá ser alcançada com segurança.

Em 2006, o Brasil alcançou a receita cambial turística de US\$ 4,32 bilhões, superior em 11,78\% ao ano de 2005 (US\$ 3,86 bilhões). Em 2005, essa receita atingiu o montante de US\$ 3,86 bilhões, superior em 19,87\% em relação ao ano anterior. (US\$ 3,22 bilhões) (...)

Com relação à meta referente à geração de 1,7 milhão de empregos e ocupações, deve-se atentar para dois fatores. A começar, coloca-se em xeque a questão do elevado nível de 
educação e qualificação exigidos pelas atividades profissionais relacionadas ao turismo, o que, dentro de uma conjuntura de subdesenvolvimento, como é o caso brasileiro, pode não gerar os benefícios esperados. Afinal, como seriam beneficiados os mais pobres, que além da baixa renda, não têm acesso a uma educação formal? No Brasil, o censo realizado em 2000 pelo IBGE registra que mais de 8 milhões de pessoas entre 15 e 59 anos de idade, dentro de um total de cerca de 146 milhões de entrevistados, são analfabetas ou possuem menos de um ano de instrução (IBGE, 2005).

Em segundo lugar, não se verifica a existência de estudos que comprovem que a formação profissional requerida para o desempenho das atividades turísticas implica, além da melhoria do nível de qualificação da mão-de-obra, uma melhor remuneração do setor pelos ganhos de produtividade obtidos. Muito pelo contrário. Baseando-se em dados fornecidos pela OMT, Sancho (1998) assevera que as ocupações ligadas ao turismo, ao passo que exigem um elevado número de horas de trabalho semanais, oferecem baixa remuneração comparativamente a outros segmentos econômicos. Entre outras características apontadas pelo autor, se incluem ainda o grande número de trabalhadores temporários; a destacada participação feminina nos postos de trabalho inferiores e baixo percentual de mulheres em cargos de maiores responsabilidades; o elevado número de trabalhadores clandestinos; e a grande presença de jovens e estrangeiros (SANCHO, 1998).

O discurso governamental apresenta o turismo como algo do interesse de todos, e a falácia de que todos ganham com o turismo é superficial e mantida apenas na aparência, pois, na essência do fenômeno, verifica-se que há contradições, pois muitos trabalhadores são explorados. Poucos discursos governamentais são acompanhados de práticas com políticas compatíveis, muitos são elaborados para ficar na retórica e causar efeitos ideológicos, de acordo com Coriolano (2006).

Nieves (2005, p. 12) afirma que a maneira mais inteligente de manter as pessoas apáticas, passivas e obedientes no turismo "tem sido a ação de divulgar as cifras dos fluxos de turistas, divisas, investimentos e empregos, o qual se reforça ampliando os dados e repetindo-os continuadamente". Aristóteles já advertia quanto "ao poder da palavra e as muitas máscaras usadas em nome da legitimação política" (RAMOS, 1989, p. 89). 
Percebe-se que a influência exercida pelos discursos sobre a população revela traços de uma política cognitiva, quando a mesma é definida como "o uso consciente ou inconsciente de uma linguagem distorcida, cuja finalidade é levar as pessoas a interpretarem a realidade em termos adequados aos interesses dos agentes diretos e/ou indiretos de tal distorção" (RAMOS, 1989 , p. 87). Barreira (2002, p. 66) reafirma tal proposição quando coloca que "o discurso do poder é constituído de modo a tornar as palavras efeitos de realidade”. Assim, governos e empresários passaram a difundir uma ideologia de que o turismo seria um caminho de desenvolvimento.

É fato que sem mudanças na política regional que se tem desenvolvido no Brasil há décadas, com um privilégio latente a dadas porções do território, não há setor da economia que possa minimizar disparidades socioeconômicas entre uma e outra região. Cruz (2001) reitera afirmando que tal modelo de desenvolvimento, ao qual se sujeita também o turismo, é concentrador de renda, excludente e perpetuador das desigualdades sócio-espaciais, e o turismo, inserido nesse modelo, reproduz, tal como qualquer outra atividade econômica, contradições do sistema.

\subsection{Categoria 2: turismo como fator de inclusão}

A inclusão social ocupa lugar de destaque no Plano Nacional de Turismo 2007/2010. Em várias metas o objetivo principal de promover a inclusão social é explicitado. Em relação à intenção de garantir o acesso ao turismo para aposentados, trabalhadores e estudantes, através de roteiros e pacotes financiados em condições facilitadas. Tal afirmação pode ser verificada no trecho a seguir:

O turismo, sobretudo, vai cumprir sua função social. Chegou a vez do turismo de inclusão. Uma inclusão na mais ampla acepção da palavra: inclusão de novos clientes para o turismo interno, inclusão de novos destinos, inclusão de novos segmentos de turistas, inclusão de mais turistas estrangeiros, inclusão de mais divisas para o Brasil, inclusão de novos investimentos, inclusão de novas oportunidades de qualificação profissional, inclusão de novos postos de trabalho para o brasileiro. Inclusão para reduzir as desigualdades regionais e para fazer do Brasil um país de todos. 
A inclusão de novos clientes no turismo brasileiro com a realização de 217 milhões de viagens no mercado interno, emerge no PNT da seguinte forma:

(...) multiplicar as oportunidades para que milhões de brasileiros possam ampliar seu olhar para dentro do Brasil. (...) trata-se agora de colocar o lazer turístico na cesta de consumo da família brasileira (...).

(...) O lançamento de pacotes diferenciados com preços promocionais para que aposentados, trabalhadores de baixa renda e estudantes possam comprar pacotes turísticos é uma medida, entre tantas outras, que tem profundo impacto no aquecimento do mercado turístico na baixa estação.

(...) Essa prioridade pela inclusão social, por meio do fortalecimento do mercado interno, é boa para todo mundo. É boa para o aposentado, que terá facilidade de viajar e curtir a melhor idade de forma merecida. É boa para o trabalhador, que poderá propiciar à sua família a abertura de novos horizontes que o turismo oferece. É boa para os estudantes, que poderão conhecer os lugares, monumentos, prédios, cidades e manifestações culturais que hoje só conhecem por meio dos livros escolares e dos meios de comunicação. É boa para o trade, que vai ter o mercado interno aquecido o ano inteiro. É boa para quem está desempregado e poderá ganhar uma oportunidade de qualificação e renda. E é boa também para o governo, que estará, assim, fortalecendo a sua política de inclusão social.

Questiona-se, a partir de tais afirmativas, que tipo de inclusão é esta pretendida pelos atores e órgãos governamentais. Cabe ressaltar que o turismo, por ser uma atividade capitalista, segue a regra de inclusão/exclusão, reproduzindo relações sociais excludentes. A maioria da população está excluída não somente das oportunidades de participar dos frutos da riqueza gerada, mas também da produção da riqueza. No entanto, esta realidade pode vir a ser modificada. Tal como citado anteriormente, Ruschmann (1997) já apontava a necessidade de o turismo ser incorporado às conquistas sociais fundamentais por ajudar a fortalecer a identidade do povo e contribuir para a paz ao integrar diferentes culturas.

Outra esfera da inclusão social proposta pelo PNT é a de novas oportunidades de qualificação profissional e a inclusão de novos postos de trabalho para o brasileiro. Isto é ilustrado na Meta 2 do PNT que é a de criar 1,7 milhão de novos empregos e ocupações. 
Para poder criar novos empregos é necessário promover a qualificação, tanto dos equipamentos quanto dos serviços turísticos:

A qualidade dos produtos turísticos está intrinsecamente associada à qualificação dos serviços prestados. O padrão de qualidade desejado deve estar referenciado na satisfação dos consumidores e nos pressupostos do turismo sustentável (...).

(...) o que implica estabelecer uma política que estimule a melhoria contínua da qualidade e segurança dos serviços prestados.

O Plano Nacional de Turismo em questão traz uma série de estratégias e medidas que representam um importante estímulo ao mercado interno. São propostas que abrem as portas do turismo nacional para que os brasileiros possam se beneficiar desse mercado seja como turista, empregado, prestador de serviço, empresário. Seja por meio de cursos de qualificação profissional, da geração de novos empregos, da incorporação das camadas de mais baixa renda como clientes do mercado turístico, seja pela adoção de políticas segmentadas para aposentados, trabalhadores e estudantes. Enfim, o turismo através das ações e propostas do PNT poderá ser um grande indutor de inclusão social.

Entretanto, sabe-se que esta inclusão social proposta pelo plano e promovida pelo turismo é uma mudança em médio prazo, uma vez que o turismo como produto do sistema capitalista e a própria lógica da economia mundial gera naturalmente a inclusão para alguns e a exclusão para muitos. Portanto, o processo de inclusão é um trabalho que deve ser realizado de forma intensificada para que possam se concretizar os objetivos propostos.

\subsection{Categoria 3: turismo como fator de crescimento/desenvolvimento}

A opção política por privilegiar o setor turismo no conjunto das atividades produtivas tem raízes práticas bem definidas. Para os agentes do governo, responsáveis pela elaboração e implementação de políticas públicas, a atividade turística se configura como um meio promissor de geração de emprego e renda, podendo contribuir para o processo de desenvolvimento de uma localidade (CASTRO, 1998). 
Dessa opção política e dos discursos repetidos à exaustão por todos os atores envolvidos na dinâmica do turismo, decorre a criação (forjada) de um senso comum de que o turismo constitui a saída econômica para regiões em vias de desenvolvimento, ou seja, uma possibilidade concreta de minimização das disparidades regionais existentes entre lugares menos e mais desenvolvidos (CRUZ, 2001).

Esta visão pode ser identificada nos objetivos dos macroprogramas que dizem respeito à Regionalização do Turismo e à Infraestrutura Pública:

(...) Potencializar os benefícios da atividade para as comunidades locais; dinamizar as economias regionais.

(...) visa assegurar o desenvolvimento turístico sustentável e integrado, melhorar a qualidade de vida da população local.

(...) Melhorar a qualidade de vida nas regiões e destinos turísticos e potencializar os benefícios decorrentes do desenvolvimento turístico.

De fato, o turismo tem em sua essência a oportunidade de dinamizar a economia de determinadas localidades, bem como promover uma melhoria na qualidade de vida da população, porém deve-se questionar quem são os atores locais envolvidos na atividade, bem como de que maneira os benefícios da atividade se (re)distribuem na região. Há ainda um hiato entre os discursos apresentados em documento e as ações governamentais e sabe-se que a dinâmica do turismo até o presente momento aponta para uma gestão do lucro centralizada nas mãos dos atores hegemônicos, sendo descentralizada somente a produção e distribuição dos bens e serviços necessários ao desenvolvimento da atividade. $\mathrm{O}$ ideal seria se governos, empresários e população considerassem, juntos, se os custos acarretados pelo turismo compensam os efeitos econômicos, que nem sempre são tão compensadores quanto se imagina.

Ainda com relação ao macroprograma de Infra-estrutura Pública, discorre-se o seguinte: 
Este programa refere-se às ações de gestão governamental relativas à promoção da integração interministerial, particularmente, Cidades (saneamento ambiental), Transportes (sistema viário), Cultura, Meio Ambiente, Integração Nacional e Defesa, entre outros Ministérios, de modo a que sejam estabelecidas parcerias intersetoriais para o atendimento das demandas relativas ao desenvolvimento das regiões turísticas, no que se refere às infra-estruturas públicas, atendidas com recursos orçamentários. Deve se desdobrar nas demais esferas da administração pública, estados e municípios, de forma a potencializar a ação do governo federal no que se refere à qualificação de base das regiões turísticas.

Ressalta-se este posicionamento como positivo dentro do que se espera do turismo como um fator que pode levar ao crescimento e desenvolvimento de uma localidade. Como o documento prevê tal integração, isso faz com que o mesmo se destaque perante outros documentos, como o PNT 2003/2007. No entanto, faz-se mister questionar de que forma tais setores se vêem articulados com o setor do turismo no momento de formação das suas agendas e proposição de ações, posto que o desenvolvimento de qualquer região pautado no turismo requer um diálogo aproximado entre todas as esferas que se inter-relacionam com o turismo, a exemplo das apontadas no PNT.

\section{Considerações Finais}

A importância do turismo na economia mundial tem se tornado inquestionável, devido aos índices de geração de divisas e renda. Porém, sua importância vai muito além do significado econômico, fazendo-se necessário pensar o turismo como ferramenta transformadora de uma localidade. No entanto, tais benefícios nem sempre serão tão expressivos quanto o esperado devido à própria conjuntura sócio-econômica vigente de primar pelo progresso econômico e acumulação de capital, em detrimento do progresso e desenvolvimento humano. Destarte, o turismo só será justo quando a sociedade for justa.

O Plano Nacional de Turismo 2007/2010 apresenta diversas propostas para a geração de novos empregos e renda, mas sabe-se que apesar da quantidade de empregos gerados pelo turismo, a remuneração para a classe trabalhadora é relativamente baixa, comparada com os 
ganhos diretos da iniciativa privada. Nesse sentido, faz-se necessário pensar numa distribuição mais igualitária da renda advinda com o turismo.

As propostas do PNT referentes à inclusão social fazem com que o turismo possa ser um grande fator de inclusão social se realmente conseguir colocar em prática as propostas estabelecidas pelo plano, que contribuem para a inclusão em todos os sentidos da palavra. No entanto, como foi discutido anteriormente, sabe-se que o turismo por ser um produto do capitalismo produz naturalmente relações sociais excludentes.

Objetivos aparentemente comuns, como erradicar a pobreza e redistribuir a renda, podem entrar em contradição, especialmente se não há uma orientação comum, indicando as escolhas estratégicas de política social, de turismo e de política econômica. Assim, urge a necessidade de atenção ao planejamento, à integração de políticas e ao diálogo entre os diversos atores que compõem a atividade turística, visto que a nova inserção internacional de economias - dentre elas a do turismo - e a maneira pela qual ela se realiza tende a ampliar a pobreza e a acentuar as desigualdades sociais, de acordo com Salama (2002).

É oportuno ressaltar, que não se pretendeu esgotar o assunto com este labor, mas antes dar um necessário passo em direção a uma maior discussão em torno de um tema sem dúvida polêmico, porém que deve permear os debates de todos os agentes envolvidos, sejam quais forem: setor público, iniciativa privada e população autóctone.

O desafio que se impõe é descobrir de que forma sair da abordagem trickle-down, com governos, empresas e mercado buscando se apropriar deste novo paradigma - o turismo sustentável, cujas idéias dão prioridade à criação de uma distribuição equitativa, construindo formas mais eficazes de redistribuição de renda, o que se traduz a partir do discurso cognitivamente correto para a prática visível e aplicada. A atividade turística não deve ser colocada como a única opção de financiamento, mas lado a lado com outros investimentos produtivos alternativos. Similarmente, o objetivo de redução da pobreza não deve ser visto de maneira estanque, distante da mensuração de benefícios gerados para outras faixas de renda. 
Nenhuma atividade econômica pode ter um fim em si mesma. Logo, o turismo não tem valia enquanto não promover a equalização social e a expansão das oportunidades e capacidades humanas, tanto dos visitantes como dos visitados.

\section{Referências}

ALVES-MAZZOTTI, A. J.; GEWANDSZNAJDER, F. 1998. O método nas ciências naturais e sociais: pesquisa quantitativa e qualitativa. São Paulo: Pioneira.

ANDRADE, J. V. 1995. Turismo: fundamentos e dimensões. São Paulo: Ática.

ARENDIT, E. J. 2002. Introdução à economia do turismo. 3. ed. Campinas: Alínea.

BANCO MUNDIAL BRASIL. 2003. Brasil: crescimento e redução de pobreza no Rio Grande do Norte: memorando econômico sobre o Estado. Brasília: Banco Mundial, 5 dez. Disponível em: $<$ http://www.obancomundial.org $>$. Acesso em: 31 mar. 2005.

BARDIN, L. 1977. Análise de Conteúdo. Lisboa: Edições 70.

BARREIRA, I. A. F. 2002. Pensamento, palavras e obras. In: CORIOLANO, L. N. M. T. O turismo nos discursos, nas políticas e no combate à pobreza. São Paulo: Annablume.

BARROS, A. J. S.; LEHFELD, N. A. S. 2000. Fundamentos de metodologia cientifica: um guia para a iniciação científica. 2. ed. São Paulo: Makron Books.

BRAMWELL, B. 2002. Selecionando instrumentos de política para o turismo sustentado. In: THEOBALD, W. F. (org.). Turismo global. 2. ed. São Paulo: Senac, p.375-391.

CASTRO, I. E. 1998. Turismo e ética. In: CORIOLANO, L. N. M. T (org.). Turismo com ética. Fortaleza: UECE, p.15-31.

CORIOLANO, L. N. M. T. 2006. O turismo nos discursos, nas políticas e no combate à pobreza. São Paulo: Annablume.

.2005. A exclusão e a inclusão social e o turismo. Revista de Turismo y Patrimonio Cultural. Espanha. v. 3, n. 2, p. 295-304. Disponível em: <http://www.pasosonline.org/Publicados/ 3205/PS080205.pdf>. Acesso em: 10 jan. 2009.

CRUZ, R. C. 2001. Política de turismo e território. 2. ed. São Paulo: Contexto.

DANTAS, A. V. S. 2001. El comportamiento de compra y el proceso de toma de decisión del turista que visita Natal, Brasil. 201 f. Dissertação (Mestrado Internacional em Turismo) - Departamento de Ciencias Económicas y Empresariales, Universidad de Las Palmas de Gran Canaria, Gran Canaria.

EMBRATUR. 2008. Estatísticas básicas do turismo.

FARIA, V. E. 2001. A política social no Brasil: uma perspectiva comparada. In: VOGEL, A.; YANNOULAS, S. C. (org.). Políticas públicas de trabalho e renda e controle democrático: a qualificação dos conselheiros estaduais de trabalho no Brasil. São Paulo: Unesp, p.97-125.

FERNANDES, I. P.; COELHO, M. F. 2002. Economia do turismo: teoria e prática. 2. reimp. Rio de Janeiro: Elsevier. 
IBGE - INSTITUTO BRASILEIRO DE GEOGRAFIA E ESTATÍSTICA. 2005. Censo demográfico 2000. Disponível em: <http://www.ibge.gov.br>. Acesso em: 02 dez. 2005.

KRIPPENDORF, J. 2000. Sociologia do Turismo. São Paulo: Aleph.

MARTINS, J. S. 2002. A sociedade a beira do abismo. Petrópolis: Vozes.

MATTAR, F. N. 1996. Pesquisa de marketing. São Paulo: Atlas.

MINISTÉRIO DO TURISMO. 2005. Turismo sustentável e o Alivio da pobreza no Brasil: reflexões e perspectivas. Disponível em: <http://institucional.turismo.gov.br/ mintur/br/ministerio/documentos/ normas.cfm> Acesso em: 10 jul. 2008

. 2007. Plano nacional de turismo 2007/2010: uma viagem de inclusão. Brasília: MTur.

MOCHON, F.; TROSTER, R. L. 1994. Introdução à economia. São Paulo: Makron Books.

NIEVES, S. G. 2005. El desarrollo turístico imaginado: Ensayos sobre un destino mexicano de litoral. México: Universidad de Guadalajara.

OLIVEIRA, H. V. 2008. A prática do turismo como fator de inclusão social. Revista de Ciências Gerenciais. São Paulo. v. 12, n. 16, p. 91-103. Disponível em: <http://sare.unianhanguera.edu.br/ index.php/rcger/article/viewFile/379/380>. Acesso em: 10 jan. 2009.

OLIVEIRA, P. S. 2002. Introdução à sociologia. 24. ed. São Paulo: Ática.

ORGANIZAÇÃO MUNDIAL DO TURISMO. 1998. Desenvolvimento de turismo sustentável: manual para organizadores locais. . 2001. Introdução ao turismo. São Paulo: Roca, 2001.

2005. Barómetro OMT de turismo mundial. Madri: OMT, v. 3, n. 2, jun. Disponível em:

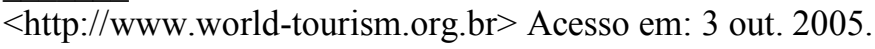

RABAHY, W. A. 2003. Turismo e desenvolvimento: estudos econômicos e estatísticos no planejamento. Barueri: Manole.

RAMOS, A. G. 1989. A nova ciência das organizações: uma reconceituação da riqueza das nações. 2. ed. Rio de Janeiro: Editora da Fundação Getúlio Vargas.

ROESCH, S. M. A. 1996. Projeto de estágio do curso de administração. São Paulo: Atlas.

RUSCHMANN, D. 1997. Turismo e planejamento sustentável: a proteção do meio ambiente. Campinas: Papirus.

SALAMA, P. 2002. Novas formas da pobreza da América Latina. In: GENTILI, P. Globalização excludente: desigualdades, exclusão e democracia na nova ordem mundial. 4. ed. Petrópolis: Vozes, p.180-222.

SANCHO, A. 1998. Introducción al turismo. Madrid: OMT.

SANTANA, G. 2005. An overview of contemporary tourism development in Brazil. In: SILVEIRA, C. E. Government policies and the development and management of tourism destinations: a case study of the brazilian policies. Disponível em: <http://www.esade.es/cedit2005/cas/est_papers.php> Acesso em: 18 abr. 2008.

SILVEIRA, M. A. T. 1999. Planejamento territorial e dinâmica local: bases para o turismo sustentável. In: RODRIGUES, A. B. (org.). Turismo e geografia: reflexões teóricas e enfoques regionais. São Paulo: Hucitec, p.87-98. 
THERBORN, G. et al. 2003. A trama do neoliberalismo: mercado, crise e exclusão social. In: SADER, E.; GENTILI, P. (org.). Pós-neoliberalismo: as políticas sociais e o estado democrático. 6.ed. São Paulo: Paz e Terra, p.139-180.

TRIGO, L. G. G.; NETTO, A. P. 2003. Reflexões sobre um novo turismo, política, ciência e sociedade. 2. ed. São Paulo: Aleph.

WAHAB, S-E. A. 1991. Introdução à administração do turismo: alguns aspectos estruturais e operacionais do turismo internacional - teoria e prática. 3. ed. São Paulo: Pioneira.

YAZBEK, M. C. 2001. Pobreza e Exclusão Social: expressões da Questão Social no Brasil. Revista Temporalis. São Paulo. v. 3. p. 33-40.

Recebido em: 24/11/2009 (1 ${ }^{\mathrm{a}}$ versão) $23 / 07 / 2010$ ( $2^{\mathrm{a}}$ versão $)$

Aprovado em: 17/11/2010 